\title{
O MOVIMENTO TEÓRICO DE \\ FERDINAND DE SAUSSURE NO PhonÉTIQUe E NO(S) CURSO(S) DE Linguística Geral
}

Thayanne Raisa Silva Lima*

(iD) https://orcid.org/0000-0002-9553-3728

Como citar este artigo: LIMA, T. R. S. O movimento teórico de Ferdinand de Saussure no Phonétique e no(s) Curso(s) de Linguística Geral. Todas as Letras - Revista de Lingua e Literatura, São Paulo, v. 22, n. 2, p. 1-12, maio/ago. 2020. DOI 10.5935/ 1980-6914/eLETDO2013422

Submissão: maio de 2020. Aceite: julho de 2020.

Resumo: O presente trabalho apresenta uma pesquisa sobre o movimento teórico de Ferdinand de Saussure acerca do aspecto fônico da língua no manuscrito Phonétique. Pautamo-nos pela ideia de movimento teórico estabelecido por Silveira (2007) para tecermos uma comparação entre o que Saussure apresenta no manuscrito de 1881-1884 e o que ele teoriza, 20 anos depois, nas suas aulas para os cursos de Linguística Geral em Genebra, no que tange ao aspecto fônico. Para tanto, utilizamos o caderno de Constantin, que frequentou as aulas na Universidade de Genebra, e o Curso de Linguistica Geral em comparação com excertos do manuscrito citado, no intuito de analisar como ambos os materiais se aproximam na discussão de questões sobre a língua - essa que mais tarde haveria de ser delimitada como o objeto para a Linguística Moderna.

Palavras-chave: Saussure. Manuscritos. Phonétique. Curso de Linguistica Geral. Aspecto fônico da língua. 


\section{INTRODUÇÃO}

$\boldsymbol{F}$

erdinand de Saussure mostra-se inserido em um momento de estudo da linguagem em que há uma grande pesquisa no campo do fônico da língua, que é o contexto da Gramática Comparada. Seu trabalho era, não diferente de sua época, focado no aspecto fônico da língua (AFL), isto é, no que é geral sobre os estudos do som. Acreditamos que, a partir dessa terminologia, conseguimos abranger o que é geral no estudo do som, fonema e acústico antes de Saussure chegar às definições de cada um desses termos.

Além disso, é importante considerar que, no século XIX, ainda não havia a distinção teórica entre linguagem, língua e fala. Assim, parece-nos adequado utilizar aqui o termo língua quando estivermos nos referindo aos estudos do século XIX. Entretanto, o termo língua não deve ser entendido anacronicamente.

Há inúmeros trabalhos do linguista suíço que tratam o AFL de forma contundente e fazem desse aspecto algo essencial para o movimento saussuriano que funda a Linguística Moderna. Um trabalho específico, no entanto, chama-nos a atenção ao tentar teorizar sobre os elementos que se desdobram a partir do AFL (fonema, acústico, som, entre outros), que é o manuscrito conhecido como Phonétique, de 1881-1884, arquivado na Universidade de Harvard e reconhecido por diferentes linguistas por sua relevância entre todos os corpora saussurianos.

Descobrimos em investigação anterior, na tese de doutoramento, que há uma relação entre os seguintes aspectos em Saussure: o teorizar sobre a língua, a obstinação quanto ao AFL e a busca pelo objeto da Linguística. Com base nessa constatação, a ideia principal deste artigo funda-se no entendimento de que esses três passos, ou melhor, um movimento saussuriano que se vale dos três, podem ser encontrados no Phonétique, mais de 20 anos antes da publicação da obra fundadora da Linguística Moderna: o Curso de Linguística Geral (CLG).

Assim, temos como objetivo examinar um movimento saussuriano que se pauta pelo trabalho com o AFL conjuntamente com outros termos e conceitos capaz de resultar na concepção de língua. Dessa forma, podemos questionar como a persistência de Saussure em teorizar sobre o AFL se relacionou com a delimitação de língua como objeto da Linguística Moderna ou até contribuiu para isso. Seria possivel encontrar no manuscrito Phonétique um movimento que se direciona para o objeto da Linguística?

Para pensarmos sobre esse movimento, apresentamos aqui uma análise do manuscrito Phonétique, presumivelmente de 1881-1884, que tem em seu cerne questões que nos parecem relevantes para a teoria que iria instaurar nos cursos de Genebra. Além disso, selecionamos esses fragmentos do manuscrito e colocamos em comparação com o estudo do AFL no caderno de Constantin (aluno que participou do III Curso de Linguística Geral ministrado em Genebra) e no próprio CLG.

Dessa forma, tecemos uma análise do movimento teórico de Saussure presente no Phonétique que se mostrou fundamental para a teoria do linguista ensinada nos cursos de Linguística Geral. À vista disso, devemos esclarecer que os fundamentos da noção de "movimento saussuriano" são embasados em Silveira (2007). Este artigo, portanto, dar-nos-á uma perspectiva sobre um movimento saussuriano que se pauta pelo AFL e por seus desdobramentos para se direcionar a uma concepção tão relevante aos estudos da Linguística Moderna, isto é, a de lingua. 


\section{O manuscrito Phonétigue}

Os manuscritos de Harvard, que possuem ao todo 638 folhas ou 995 páginas, são compostos por um conjunto de nove arquivos bem variados, nos quais há "cadernos, fichas, envelopes, cartas e folhas soltas de formatos e gramaturas diversas" (D’OTTAVI, 2017, p. 154). De acordo com Marchese (1995), esses manuscritos foram arquivados na biblioteca de Houghton Library em 1968, embora não haja certeza se a numeração dos arquivos (de 1 a 9) foi feita pelos catalogadores.

Outro ponto que suscita interesse histórico é sobre como esses manuscritos chegaram a Harvard; quanto a isso, D'Ottavi (2017, p. 155) assegura o seguinte:

Jakobson declarou que a Biblioteca de Houghton Library teria sido, genericamente, "agraciada" com a coleção pelos filhos de Ferdinand - Jacques (1892-1969) e Raymond (1894-1971) de Saussure -, ao passo que, em outra ocasião, ele falou explicitamente em "doação". A nota oficial da Biblioteca qualificou a natureza dessa transação como "compra", que teria sido efetuada pelos Amigos do fundo bibliográfico do Harvard College, e assinalou até mesmo o montante da transação: 2.000 dólares.

Segundo D’Ottavi (2017), nos arquivos 1 ao 9 foram encontrados os seguintes títulos: 1. Du génitif absolue en-sanscrit (1880-1881), tese apresentada por Saussure à Faculdade de Filosofia da Universidade de Leipzig em 1880; 2. Essai pour réduire les mots $d u$ grec, du latin et de l'allemand à um petit nombre de racines (1874), a primeira empreitada de Saussure em linguística e o documento mais velho entre os manuscritos de Harvard; 3. Notes de lexico graphies sanscrits, notas sobre as formas das raízes sânscritas; 4. Lecture de Mémoire par G. Guieysse (1889), obra de Georges Guieysse, um dos alunos de Saussure em Paris; 5. Notes d'arménien, notas sobre o problema do $-k$ final armênio; 6. Notes on Linguistics, intitulado pelos arquivistas (em inglês) de notas sobre assuntos variados; 7 . continuação do caderno 3; 8. Phonétique (1881-1884), no qual constam a noção e as implicações do conceito de "fonema"; 9. Message d'Alphonse de Candolle, mensagem de Alphonse de Candolle (botânico genebrino) a Saussure.

O trabalho de diferentes linguistas com esses manuscritos tem início desde a data de sua catalogação em Harvard, a saber:

Depois do anúncio de Jakobson (1969) e das notas esparsas de Davis (1978; 1990; 1992), uma primeira apresentação homogênea do fundo foi feita por Marchese (1990), apresentação revista e substituida por notas introdutórias a sua edição de uma das pastas harvardianas (Marchese 1995: VII-XI; ver § 2.2). O "Guia" da Biblioteca Houghton oferece um ponto de partida oficial para a exploração do material, ao mesmo tempo que a via maior de acesso aos manuscritos saussurianos de Harvard é, ainda hoje, a edição antológica publicada no início dos anos 1990 por Parret (1993) (D’OTTAVI, 2017, p. 102).

De todo esse compilado de folhas, o que nos chama a atenção é o arquivo 8, constituído por cinco cadernos com o título Phonétique. Para Marchese (1995), provavelmente esse conjunto de anotações recebeu esse nome de Saussure e presume-se ser datado de 1881-1884. Para D'Ottavi (2017), esses cinco cadernos não sugerem estar em sequência, porém o formato das folhas e a escrita mostram-se de forma homogênea, além do formato do texto que segue critérios recorrentes; em suma, o conjunto das folhas apresenta certa unidade.

As questões trazidas pelo genebrino acerca do AFL e dos desdobramentos desse aspecto são essenciais ao presente estudo, particularmente pela dedução 
de corresponderem a um momento decisivo na conceituação de termos que, de acordo com nossa hipótese, encaminham a pesquisa de Saussure rumo ao seu objeto. Por esse motivo, fazemos nota aqui de como esse material apresenta uma relação com as aulas de Saussure que cunharam a fundação da Linguística Moderna. Para tanto, estabelecemos um paralelo entre alguns fragmentos do manuscrito, do caderno de Constantin e do CLG e deixamos a seguinte questão: haveria no Phonétique, ainda tão cedo nos estudos saussurianos, algum indício do estudo da língua, objeto da Linguística Moderna?

\section{O Phonétigue e o(s) Curso(s) de Linguística Geral}

Interessa-nos investigar como esse material saussuriano com o título Phonétique insere-se nesse contexto de produção que se centra no AFL e desenvolve questões sobre a Linguística e, mais, como o manuscrito faz uma ponte entre esse aspecto e o objeto da linguística: a lingua. Vale lembrar que o trabalho de Saussure não se dá de forma linear, não há no linguista uma ideia pronta que começa nos seus primeiros trabalhos e evolui até seus cursos de Linguística Geral; por esse motivo, acreditamos que pautar qualquer noção saussuriana requer passar pela ideia de movimento estabelecida por Silveira (2007).

Necessitamos, portanto, esclarecer que, para Silveira (2007), a ideia de movimento teórico em Saussure deve ser pautada pela análise de vários aspectos da sua obra. Além disso, a autora elege um lugar privilegiado de análise quando afirma o seguinte:

[...] não é possivel dizer do movimento de Saussure quando se nega o CLG e se parte para a busca do "Saussure verdadeiro" ou quando se ignoram os pontos de tensão presentes na edição. Dessa forma, é condição, para a apreensão do movimento que funda a linguística, um reconhecimento do CLG nessa fundação, bem como uma subversão da sua linearidade. [...] pensamos que vale a pena retornar ao CLG e ali pontuar alguns momentos de tensão com o objetivo de situar o movimento de fundação da linguística (SILVEIRA, 2007, p. 56-57, grifo nosso).

Dessa maneira, é possivel pensarmos que, se a autora observa um movimento saussuriano ao se dedicar aos "momentos de tensão do CLG", acreditamos na possibilidade de levantarmos os pontos de tensão presentes na discussão sobre o AFL no Phonétique, de modo a localizarmos as marcas de um movimento que se tornou essencial para a delimitação de um objeto para a Linguística já em 1881-1884.

Cabe-nos esclarecer, portanto, qual a importância dos cadernos dos alunos para a pesquisa saussuriana e como eles podem se relacionar com o manuscrito citado. Ora, o trabalho de Saussure ficou conhecido por intermédio do Curso de Linguistica Geral, livro que foi editado e publicado por Charles Bally e Albert Sechehaye em 1916. As fontes dessa obra partiram tanto dos cadernos dos alunos que participaram dos três cursos de Linguística Geral em Genebra como de anotações pessoais de Saussure doadas aos editores por sua esposa. A obra publicada repercutiu pelo mundo todo dando destaque à teoria saussuriana e, consequentemente, é responsável por fundar a Linguística Moderna.

Os cadernos dos alunos que participaram das aulas em Genebra de 1907-1911 e o CLG são materiais bastante significativos: o primeiro faz parte das notas investigadas pelos editores na confecção do livro póstumo de Saussure e o segundo divulga o trabalho do linguista, fatos que reafirmam a necessidade de 
compreendermos como o AFL e seus desdobramentos são abordados até chegarmos ao objeto da linguística em ambos os materiais.

Os cursos de Linguística Geral foram ministrados por Saussure de 1907 a 1911, sendo o primeiro no ano de 1907, o segundo em 1908-1909 e o terceiro em 1910-1911. A partir da anotação dos cadernos dos alunos ${ }^{1}$ que participaram desses cursos, foi possivel que Bally e Sechehaye trabalhassem de forma mais detalhada na edição do CLG, visto que essas anotações retratam a cadeia de conceitos responsáveis pela fundação da Linguística Moderna.

Passamos agora para uma análise de um fragmento do caderno do Constantin do III Curso de Linguística Geral, do CLG e de fragmentos do manuscrito Phonétique no intuito de estabelecermos um movimento teórico possivel no trabalho de Saussure; focamos, assim, os pontos de tensão que nos parecem cruciais para o surgimento do objeto lingua.

Vejamos no caderno de Constantin a figura que, a nosso ver, é fundamental à noção de língua:

Figura 1 - Trecho do caderno de Constantin

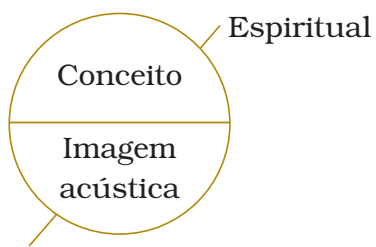

Material (no sentido do sensorial, fornecido pelos sentidos, mas não do físico)

Fonte: Saussure (apud CONSTANTIN, 1910-1911, p. 53).

Lembramos, assim, que a imagem acústica é dada "na acepção do sensorial, fornecida pelos sentidos, mas não do físico", e sua contraparte é o conceito que Saussure denomina espiritual. No Phonétique notamos um fragmento em que o linguista dá destaque à "unidade fonética = unidade acústica de sensação/do fenômeno físico", como mostra a Figura 2.

Figura 2 - Trecho do manuscrito (MsFr 266)

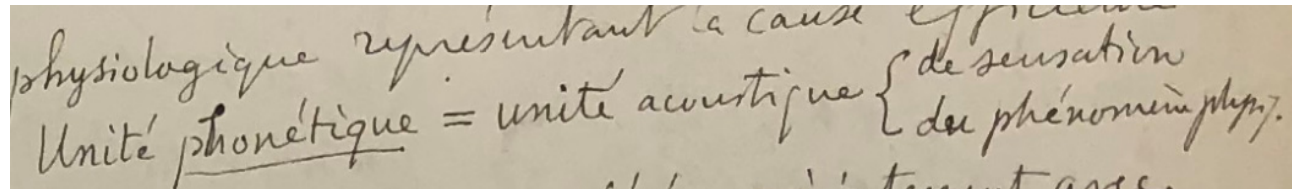

Unidade fonética $=$ unidade acústica $\left\{\right.$ de sensação/do fenômeno físico ${ }^{2}$ (tradução nossa). Fonte: Saussure (1880-1890, f. 67).

Ora, é possivel notar que Saussure mantém sua ideia de duplicidade, e, dessa vez, ela é marcada na unidade acústica, a saber: sensação e fenômeno físico, o que difere do que Jakobson $(1969$, p. 8) apresenta em seu texto quando demonstra que nesse manuscrito há uma aplicação "de forma consistente do termo

1 Preferimos trabalhar nesse momento com os cadernos dos alunos editados por Komatsu e Wolf pela facilidade de acesso ao material. A edição que contém a base da edição do CLG de Estanislao Sofia (2015) com o título La "Collation Sechehaye" du 'Cours de Linguistique Générale' de Ferdinand de Saussure está indisponível para venda.

2 Unité phonétique = unité acoustique $\{$ de sensation/su phénomène physique. 
'acústico' unicamente ao nivel sensorial”. Entretanto, esse fato não impede de pensarmos em uma separação da unidade acústica que deve ser marcada tanto pelo fenômeno físico como pela sensação.

Poderiamos deduzir, dessa forma, que ou o conceito ou a imagem acústica seriam, mais tarde no CLG, essa parte chamada por Saussure de "unidade acústica de sensação", mas o fenômeno físico, como vimos no caderno de Constantin, fica excluído da concepção de signo. No Phonétique, por sua vez, o genebrino coloca várias porções dessa unidade acústica no canto dessa mesma folha, vejamos com ele.

Figura 3 - Trecho do manuscrito (MsFr 266)

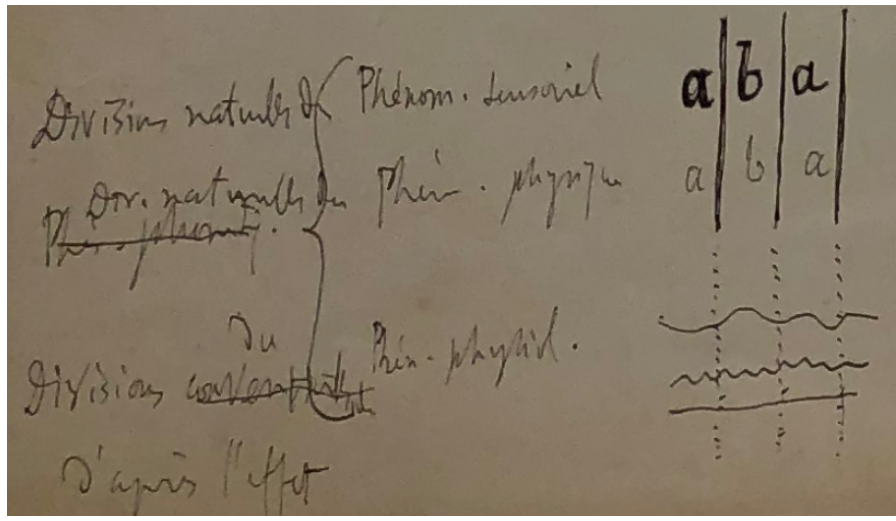

Divisão natural do \{Fenômeno sensorial

Divisão natural do \{Fenômeno físico

Divisão de depois do efeito \{Fenômeno fisiológico ${ }^{3}$ (tradução nossa).

Fonte: Saussure (1881-1884, f. 67).

Assim, fica claro que para Saussure há três divisões possiveis no manuscrito: 1. a divisão natural do fenômeno sensorial que nos parece remeter a algo dos sentidos, do nivel sensorial que vemos na concepção de signo no caderno de Constantin; 2. a divisão natural do fenômeno físico, que é natural e ao mesmo tempo físico, isto é, não poderia ser assimilado com uma contraparte do signo daquele mesmo caderno; e 3. a divisão de depois do efeito, fenômeno fisiológico, isto é, uma outra porção que se difere do físico parece, a nosso ver, o mecanismo do corpo possivel de produzir o som, portanto, depois do "efeito".

O termo "efeito" é retomado por Saussure nas aulas de Genebra, como vemos no caderno de Constantin: "o fonema compõe-se ao mesmo tempo de certa soma de movimentos articulatórios e de certo efeito acústico dado” (SAUSSURE apud CONSTANTIN, 1910-1911, p. 56). O fonema, portanto, anos depois do Phonétique, é caracterizado nos cursos de Genebra perante os movimentos articulatórios, que podem ser facilmente associados ao fenômeno físico e ao fisiológico retratados em 1881-1884 depois do efeito. Contudo, não encontramos nesse fragmento uma relação entre o fonema e o fenômeno sensorial; acreditamos que no Phonétique aparece essa terceira característica, fenômeno sensorial que, sim, é encontrada a partir da pesquisa com o AFL, mas que depois poderia ser um indício do

3 Division naturelle dul Division naturelle dul Division d'apres l'effet \{ Phénomène sensoriell Phénomène physique/ Phénomène physiologique. 
que encontramos no CLG, ou seja, o sensorial relacionado à imagem acústica "material (no sentido sensorial, fornecido pelos sentidos, mas não do físico)"; daí o fônico da lingua parece passar por uma transformação.

Esse ponto de tensão, que marca uma terceira característica de um fenômeno - sensorial -, pode ser encontrado mais uma vez e com mais detalhes no Phonétique, como ilustra a Figura 4.

Figura 4 - Trecho do manuscrito (MsFr 266)

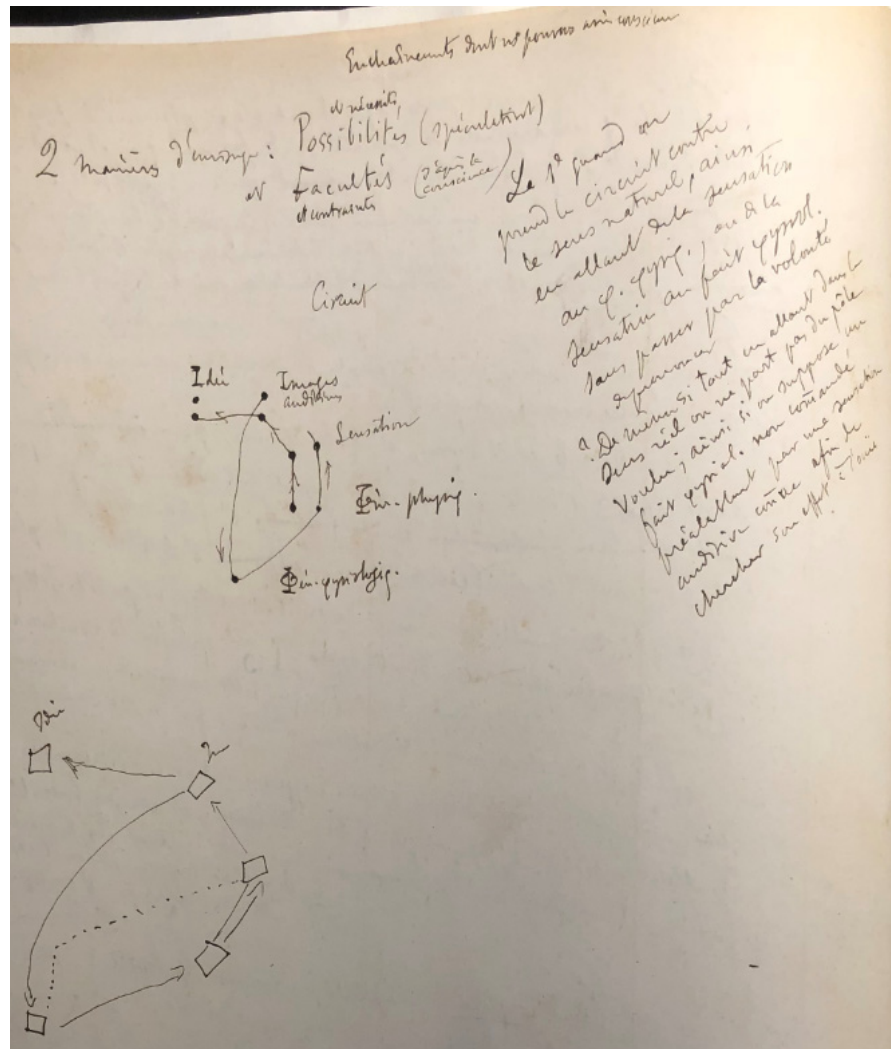

Encadeamentos dos quais podemos estar cientes

2 maneiras de considerar: Possibilidades e necessidade (especulativamente)

e Faculdades e restrições (segundo a consciência)

$\mathrm{O} 1^{\circ}$ quando tomamos o circuito contra o sentido natural, indo, assim, da sensação para o fenômeno físico, ou da sensação para o fato fisiológico, sem passar pela vontade do pronunciante.? Do mesmo modo, se, embora indo no sentido real, não partimos do polo desejado; assim, se supusermos um fato fisiológico não previamente ordenado por uma sensação auditiva contínua, a fim de buscar seu efeito sobre a audição

Ideia; Imagens auditivas; sensação; fenômeno físico; fenômeno fisiológico ${ }^{4}$ (tradução nossa).

Fonte: Saussure (1881-1884, f. 54v).

4 enchaînements dont nous pouvons avoir conscience 2 manières d'envisager: possibilité et necessité (spéculativement) et Facultés et contraintes (d'après la conscience) Le 1er quando on prend la circuit contre le sens naturel, ainsi en allant de la sensation au phénomème physique, ou de la sensation au fait physiologique, sans passer par la volonté du prononceur

De même si tout en allant dans e sens réel on ne part pas du pôle voulu; ainsi si on suppose un fait physiologique no commandée préalablement par unse sensation auditive cnnue afin de chercher son effet à l'ouïe

Idée; Images auditives; Sensation; Phénomène-physique; Phénomène-physiologique 
Eis que encontramos tanto nessa gravura do desenho de um circuito como na explicação de como se dá o que Saussure chama de "encadeamento", outro ponto que nos chama a atenção. Vemos que há indícios de uma questão essencial no CLG: o circuito da fala, presente no capítulo III da Introdução que versa sobre o objeto da linguística e que, de acordo com De Mauro (1967), tem como fonte três lições do terceiro Curso de Linguística Geral. Vejamos no CLG como esse circuito é retratado:

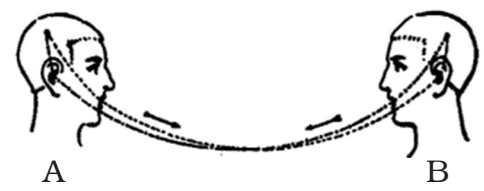

O ponto de partida do circuito se situa no cérebro de uma delas, por exemplo A, onde os fatos de consciência, a que chamaremos conceitos, se acham associados às representações dos signos linguísticos ou imagens acústicas que servem para exprimi-los. Suponhamos que um dado conceito suscite no cérebro uma imagem acústica correspondente: é um fenômeno inteiramente psíquico, seguido, por sua vez, de: um processo fisiológico: o cérebro transmite aos órgãos da fonação um impulso correlativo da imagem; depois, as ondas sonoras se propagam da boca de A até o ouvido de B: processo puramente físico. Em seguida, o circuito se prolonga em $B$ numa ordem inversa: do ouvido ao cérebro, transmissão fisiológica da imagem acústica; no cérebro, associação psíquica dessa imagem com o conceito correspondente (SAUSSURE, 2012, p. 43).

Ao compararmos os dois circuitos, vemos que ainda há várias distinções entre eles. Não temos no Phonétique a palavra "psíquico", no entanto acreditamos que, ao esboçarmos o circuito com setas, podemos ser orientados a compreender a seguinte sequência: Imagem auditiva $\Rightarrow$ Fenômeno fisiológico $\Rightarrow$ Fenômeno físico $\Rightarrow$ Sensação $\Rightarrow$ Ideia. Esse seguimento, a nosso ver, separa cada evento que acontece no circuito como contínuo, isto é, um acontece para o próximo acontecer, o que nos leva a crer na distinção entre cada um dos elementos dessa trajetória.

Dessa forma, é possivel afirmarmos que, nessa folha, a sensação não está ligada aos fenômenos físicos/fisiológicos do Phonétique, os quais nos parecem associados aos processos físicos e fisiológicos descritos no circuito representado no CLG. Entretanto, a sensação também acontece antes da ideia; seria ela, portanto, o que no CLG Saussure propõe como a transmissão fisiológica da imagem acústica? Mas ao mesmo tempo esbarramos na noção dada por Constantin de que a imagem acústica está ligada ao sensorial; teríamos, por conseguinte, na palavra sensação uma nuance de algo que começa a se afastar do puramente físico?

Por mais que as perguntas nos instiguem a uma resposta fácil, acreditamos que elas não possam ser respondidas a partir somente dessa base de dados de Saussure. Apesar disso, vemos outro ponto de tensão crucial para a definição do objeto da Linguística. Se nesse fragmento do Phonétique temos um esboço do circuito da fala, julgamos fundamental fazer a seguinte pergunta: em que medida discorrer sobre esse circuito leva-nos ao objeto da Linguística?

É fato que há no cerne dessa questão outra bastante cara aos linguistas dedicados à pesquisa saussuriana, isto é, a relação entre língua e fala e sua importância. Silveira (2013, p. 49) ressalta que "essa distinção entre língua e fala é, portanto, o ponto central da operação saussuriana e o que lhe lega, atualmente, 
o lugar de fundador da Linguística entre outras coisas por cernir o objeto desta ciência [...]". A autora, ao observar o circuito da fala no CLG, acrescenta:

Esses dois processos distintos, um fisiológico e físico e outro psíquico, dividem língua e fala. Assim, propriamente e totalmente psíquica é a associação entre o significante e o significado que constituirá os signos, que por sua vez engendrarão um sistema, ou seja, a língua como um sistema de signos. Fisiológico e fisico são os processos que constituem o funcionamento da fala (SILVEIRA, 2013, p. 50).

Ao pensarmos nessa observação, é possivel creditar ao movimento teórico de Saussure do Phonétique um trabalho de investigação dos elementos do AFL que chegam a traços responsáveis, mais tarde, por determinar os aspectos da fala. Além disso, é a partir desse movimento que chegamos à língua, como relata Silveira (2013, p. 50):

A fala, no seu aspecto empírico, fisiológico e individual, é secundária na constituição do objeto da Linguística. A fala, no seu aspecto psíquico social, é o que constitui a língua e é o essencial do objeto da Linguística. Sim, ele parece tomar uma posição em relação a essas concepções: no que diz respeito à concepção de fala que considera os órgãos vocais e a fonação, ou seja, os aspectos fisiológicos e físicos da fala, ele é categórico: são estranhos à língua como sistema e não o afetam em si (Saussure, 2012:50). Ou seja, o conceito de fala do seu tempo deu lugar a um conceito de língua e fala, e o conceito de língua, com todos os mecanismos evidenciados por Saussure, é essencial em relação à fala que, como fisiológica/fisica e individual, é acidental.

Ora, dessa maneira constatamos que o movimento por nós investigado dá à pesquisa saussuriana uma perspectiva essencial para a definição de língua. Visto que Saussure está inserido em um contexto de pesquisas voltadas para as evoluções fonéticas ou suas mudanças, isto é, o que compete ao AFL; além do estabelecimento de leis dessas, a novidade de encontrar um objeto para a linguística e concebê-lo como o encontramos no CLG, a nosso ver, teve em seu cerne uma grande relação com as pesquisas fonéticas do século XIX.

A partir da obstinação de Saussure com o AFL, das críticas com o fazer empírico e da necessidade de distinção entre os termos que circundavam os estudos foneticistas, foi possivel dar outra perspectiva para a pesquisa saussuriana; daí o linguista começa a notar outras questões fundamentais responsáveis por traçar um esboço que chegaria ao objeto da Linguística.

Todavia, como poderíamos pressupor que esse movimento teórico assinalado por nós em diferentes pontos do manuscrito Phonétique pode nos levar à sincronia? Devemos primeiro expor como Saussure (2012, p. 194) vê a diacronia:

A Fonética, e toda a Fonética, constitui o primeiro objeto da Lingüística diacrônica; com efeito, a evolução dos sons é incompatível com a noção de estado; comparar fonemas ou grupos de fonemas com o que foram anteriormente equivale a estabelecer uma diacronia. A época antecedente pode ser mais ou menos próxima; mas quando uma e outra se confundem, a Fonética deixa de intervir; só resta a descrição dos sons de um estado de língua, e compete à Fonologia levá-la a cabo.

Dito isso, podemos pensar que o Phonétique talvez tenha sido uma tentativa de Saussure de trabalhar a diacronia, mostrar a evolução dos sons e comparar 
os fonemas, realizar o seu prazer histórico ${ }^{5}$. Contudo, vimos que o linguista vai para além desses caminhos. Na diacronia, o objeto de pesquisa é de domínio histórico, faz-se nela um estudo de termos que se sucedem e que são substituídos um por outro no tempo; pode-se ignorar o sentido das palavras, preocupa-se somente com seu invólucro material e corta "frações fônicas sem perguntar se elas têm significado" (SAUSSURE, 2012, p. 194). Tal circunstância nos dirige aos estudos dos comparatistas como Grimm e Schleicher, pois era esse o ponto de vista em relação aos estudos da língua por eles concebido; para Saussure, tratava-se de uma linguística que ele chama de evolutiva. A sincronia, por sua vez,

[...] conhece somente uma perspectiva, a das pessoas que falam e todo o seu método consiste em recorrer-lhes o testemunho; para saber em que medida uma coisa é uma realidade, será necessário e suficiente averiguar em que medida ela existe para a consciência de tais pessoas (SAUSSURE, 2012, p. 132).

Apresentar a sincronia a partir da perspectiva do sujeito falante coloca-nos diante do fato de que, para "o indivíduo falante, a sucessão dele no tempo não existe: ele se acha diante de um estado" (SAUSSURE, 2012, p. 123). Esse ponto apresenta-nos a questão que abordamos na pesquisa com o Phonétique: vimos que Saussure esboça algumas marcas em direção à fala, ou ao sujeito falante, e isso acontece porque encontramos o que ele chama de "sensação" ou "fato sensorial" muitas vezes relacionado a algo ligado ao sentimento, provavelmente do sentimento do sujeito falante; esses termos não são somente um fenômeno físico.

Outrossim, procurar estabelecer diferenças, oposições e relações, marcar o valor das regras fonéticas, pensar nas consequências das suas regras mostra-nos uma posição de Saussure no manuscrito que o afasta de um foneticista/comparatista e o aproxima do passo característico em suas folhas escritas: aquele que marca sua teoria da Lingua.

Ademais, assinalar os fenômenos do AFL entre acústico, fisiológico e físico, oscilar acerca das distinções entre esses termos, delinear um circuito que os separa e apresentar o sensorial associado a acústico com um traço que ora aproxima-se de um dado físico, ora distancia-se dele, mas também nos dá indício de que ele pode ser aplicado à sensação - aquela marcada como a imagem acústica do signo anos mais tarde - desvenda um movimento que vai para além do sensorial, busca a língua. O suiço movimenta-se em direção a fazer linguística e não somente a se desvelar sobre seu prazer histórico.

\section{À GUISA DE CONCLUSÃo}

O objetivo deste artigo parecia uma tarefa desafiadora: relacionar o conteúdo de um manuscrito tão cedo nos trabalhos saussurianos, isto é, 1881-1884, com o caderno de Constantin e o CLG, ambos de mais de 20 anos depois da escrita do Phonétique. Contudo, conseguimos observar que a obstinação de Saussure pelo AFL era tanta que intencionalmente, ou não, o novo para a Linguística foi tomando forma desde os trabalhos mais antigos da carreira do linguista.

Devemos nos atentar ao fato de que, nas folhas manuscritas do Phonétique, a ideia de Saussure não parecia ser de fazer Linguística Geral, como vemos pelo

\footnotetext{
O "prazer histórico" é aquele a que Saussure se refere na carta endereçada a A. Meillet de 4 de janeiro de 1894, em que aponta: "Incessantemente, essa inépcia da terminologia corrente, a necessidade de reformá-la e de mostrar dessa forma que tipo de objeto é a língua em geral vêm arruinar meu prazer histórico [...]" (cf. GODEL, 1969, p. 31).
} 
próprio nome do manuscrito, ou por se tratar, a princípio, da evolução dos sons e comparação de fonemas. Ao menos esse tipo de pesquisa era a postura dos pesquisadores da língua na época, assim como Saussure deixa claro nos cursos de Genebra; nessa perspectiva, é notória a persistência do linguista no tratamento com o AFL e como seus elementos despontam de uma forma que várias vezes nos remete à teorização sobre a língua.

O AFL é, assim, um dos pontos de partida da pesquisa saussuriana, com certeza não é o único e, mais, ele vai se modificando. Isso acontece porque quando chegamos ao conceito de imagem acústica não é possivel afirmar que temos o AFL; o fônico é suspenso nessa questão e agora estamos diante de uma das partes do signo que é psíquica.

O movimento teórico do genebrino aqui descrito leva-nos a depreender que abordar as questões históricas, fonéticas da língua dá indícios do mesmo processo dos cursos de Linguística Geral. Em outras palavras, primeiro Saussure trabalha as questões históricas e depois se aprofunda nas questões gerais que seriam mais tarde associadas à teoria da língua. A nosso ver, a retomada do Phonétique nas aulas pode evidenciar uma busca de Saussure para que as questões gerais sobre a língua pudessem vir à tona e, a partir daí, surgir todos os conceitos e termos que compõem o sistema da língua.

Sobretudo, vale ressaltar que há um movimento teórico nos escritos saussurianos que nos conduzem à definição do objeto da Linguística. Tal constatação também é observada por Silveira (2007, p. 135), que, ao analisar alguns manuscritos de Saussure de 1891, destaca que o "movimento que dá certo lugar ao geral e ao particular nos estudos da linguagem não é sem efeitos para a definição do objeto da linguística". Ainda, Surreaux (2013) e Milano (2015), ao refletirem sobre o AFL, mostram como o linguista chegaria ao conceito de sistema (sistema de sons - sistema de relações internas - sistema da língua).

No Phonétique, não é diferente, há um trabalho que nos direciona à busca do objeto da Linguística; Saussure e sua obstinação com o AFL nos encaminham a perceber sua necessidade de mudança que, intencional ou não, é contumaz e marca o movimento teórico saussuriano em direção à língua.

\section{Ferdinand de Saussure's theoretical movement on Phonétigue and in the Genenral Linguistics Course(s)}

Abstract: This article presents a research about Ferdinand de Saussure's theoretical movement towards the phonic aspect of language in the Phonétique's manuscript. We are guided by the idea of theoretical movement established by Silveira (2007) in order to compare what Saussure presents in his manuscript from 1881-1884 and, more than 20 years later, in his courses of General Linguistics which he taught in Geneva with regard to the phonic aspect. To accomplish that, we use Constantin's notebook, which attended Saussure's classes at Geneva's University, and the Course in General Linguistics in comparison with the manuscript's excerpts in order to analyze how both materials approach issues about language - which later on would be part of the Modern Linguistics' object establishment.

Keywords: Saussure. Manuscripts. Phonétique. Course in General Linguistics. Phonic aspect of the language. 


\section{REFERÊNCIAS}

DE MAURO, T. Cours de Linguistique Générale: édition critique préparée par Tullio de Mauro. Paris: Payot, 1967. 520 p.

D'OTTAVI, G. Nine easypieces: os documentos de Saussure em Harvard. In: ALTMAN, C.; TESTA-TORELLI, L. (org.). Cadernos de Historiografia Linguística do CEDOCH: por ocasião do centenário do Curso de Linguística Geral (1916). São Paulo: FFLCH/USP, 2017. p. 153-177.

GODEL, R. Les sources manuscrites du cours de linguistique générale de F. de Saussure. 2. ed. Genebra: Librairie Droz, 1969. 282 p.

JAKOBSON, R. Saussure's unpublished reflections on phonemes. Cahier Ferdinand de Saussure. Revue de linguistique générale, Genebra, n. 26, p. 5-14, 1969.

MARCHESE, M. P. Introduzione. In: Phonétique: Il manoscritto di Harvard Houghton Library bMS Fr 266. 8. ed. Maria Pia Marchese. Padova: Unipress, 1995. p. VII-XXIV.

MILANO, L. Fonético e fonológico em Saussure: o lugar do fônico no Curso de Linguistica Geral. Eutomia, Recife, v. 16, n. 1, p. 245-258, 2015.

SAUSSURE, F. Phonétique: Ms Fr 266 (8) (73-7023). Cambridge: Houghton Library, 1881-1884. 177 p.

SAUSSURE, F. Troisième Cours de Linguistique Générale (1910-1911): d'après les cahiers d'Emile Constantin/Saussure's Third Course of Lectures on General Linguistics (1910-1911): from the notebooks of Emile Constantin. Edição e tradução Eisuke Komatsu e Roy Harris. Inglaterra: Pergamon Press, 1993. 173 p. SAUSSURE, F. Curso de Linguistica Geral. 27. ed. Tradução Antônio Chelini, José Paulo Paes e Izidoro Blikstein. São Paulo: Cultrix, 2012 [1916]. 279 p.

SILVEIRA, E. M. As marcas do movimento de Saussure na fundação da linguística. Campinas: Mercado de Letras, 2007. 168 p.

SILVEIRA, E. M. O lugar do conceito de fala na produção de Saussure. In: FIORIN, J. L.; FLORES, V. do N. (org.). Saussure: a invenção da linguística. São Paulo: Contexto, 2013. p. 45-58.

SURREAUX, L. M. O rastro do som em Saussure. Nonada: Letras em Revista, Porto Alegre, v. 20, n. 1, p. 285-295, 2013. 